\title{
Implementation of Neurocritical Care Is Associated With Improved Outcomes in Traumatic Brain Injury
}

\author{
Mypinder S. Sekhon, Peter Gooderham, Brian Toyota, Navid Kherzi, Vivien Hu, \\ Vinay K. Dhingra, Morad S. Hameed, Dean R. Chittock, Donald E. Griesdale
}

\begin{abstract}
Background: Traditionally, the delivery of dedicated neurocritical care (NCC) occurs in distinct NCC units and is associated with improved outcomes. Institution-specific logistical challenges pose barriers to the development of distinct NCC units; therefore, we developed a consultancy NCC service coupled with the implementation of invasive multimodal neuromonitoring, within a medical-surgical intensive care unit. Our objective was to evaluate the effect of a consultancy NCC program on neurologic outcomes in severe traumatic brain injury patients. Methods: We conducted a single-center quasi-experimental uncontrolled pre- and post-NCC study in severe traumatic brain injury patients (Glasgow Coma Scale $\leq 8$ ). The NCC program includes consultation with a neurointensivist and neurosurgeon and multimodal neuromonitoring. Demographic, injury severity metrics, neurophysiologic data, and therapeutic interventions were collected. Glasgow Outcome Scale (GOS) at 6 months was the primary outcome. Multivariable ordinal logistic regression was used to model the association between NCC implementation and GOS at 6 months. Results: A total of 113 patients were identified: 76 pre-NCC and 37 post-NCC. Mean age was 39 years (standard deviation [SD], 2) and 87 of 113 (77\%) patients were male. Median admission motor score was 3 (interquartile ratio, 1-4). Daily mean arterial pressure was higher $(95 \mathrm{mmHg}$ [SD, 10]) versus $(88 \mathrm{mmHg}[\mathrm{SD}, 10], \mathrm{p}<0.001)$ and daily mean core body temperature was lower $\left(36.6^{\circ} \mathrm{C}[\mathrm{SD}, 0.90]\right)$ versus $\left(37.2^{\circ} \mathrm{C}[\mathrm{SD}, 1.0], \mathrm{p}=0.001\right)$ post-NCC compared with pre-NCC, respectively. Multivariable regression modelling revealed the NCC program was associated with a 2.5 increased odds (odds ratios, 2.5; 95\% confidence interval, 1.1-5.3; $\mathrm{p}=0.022$ ) of improved 6-month GOS. Conclusions: Implementation of a NCC program is associated with improved 6 month GOS in severe TBI patients.
\end{abstract}

RÉSUMÉ: Contexte: La prestation de soins intensifs neurologiques (SIN) spécialisés s'effectue habituellement dans diverses unités et est associée à une évolution favorable de l'état des patients. Cela dit, les difficultés logistiques propres à chaque établissement constituent autant d'obstacles à la mise sur pied d'unités de SIN. Nous avons par conséquent créé, au sein d'un service de soins intensifs formé de médecins et de chirurgiens, un service-conseil et mis en œuvre un programme de monitorage multimodal. Notre objectif était d'évaluer l'impact de ce service-conseil quant à l'évolution de patients victimes de sévères traumatismes crâniens. Méthodes: Nous avons mené, dans un seul centre hospitalier, une étude quasi expérimentale non-contrôlée divisant ces patients (score à l'échelle de Glasgow $\leq$ ) en deux groupes : les patients n'ayant pas reçu de SIN et ceux en ayant bénéficié. Le programme incluait une série de consultations avec des médecins spécialisés en SIN (neurointensivists) et des neurochirurgiens ainsi qu'un monitorage multimodal. Diverses données (de nature démographique et neurophysiologique mais se rapportant aussi à la gravité des blessures et aux types d'interventions thérapeutiques) ont alors été collectées. Au bout de 6 mois, le score à l'échelle de Glasgow fut le principal indicateur d'évolution. La technique de régression logistique ordinale à variables multiples fut utilisée pour modéliser le lien existant entre la mise en œuvre dudit programme et les scores à l'échelle de Glasgow. Résultats: Un groupe formé de 113 patients a été retenu ; de ce nombre, 76 n'avaient bénéficié d'aucun SIN. L'âge moyen de tous les patients était de 39 ans (écart type [ÉT], 2). Notons que 87 d'entre eux (77\%) étaient des hommes. Au moment de leur admission, leur score médian à l'échelle de Glasgow était de 3 (rapport interquartile, 1-4). Si l'on compare les patients ayant bénéficié de SIN à ceux n'en ayant pas reçu, on remarque que la pression artérielle moyenne des premiers était quotidiennement plus élevée $(95 \mathrm{mmHg}$ [ÉT, 10]) que celle des derniers (88 mmHg [ÉT, 10], $p<0,001)$. De plus, la température moyenne centrale des patients ayant bénéficié de SIN s'est avérée plus basse $\left(36,6^{\circ} \mathrm{C}[\mathrm{E} T, 0,90]\right)$ que celle des autres patients $\left(37,2^{\circ} \mathrm{C}[E ́ \mathrm{~T}, 1,0], p=\right.$ 0,001). À l'aide d'une régression à variables multiples, il a été démontré que le programme de SIN était associé à une probabilité 2,5 plus élevée (risque relatif approché : 2,5; IC 95\%, 1,1-5,3; $p=0,022$ ) d'obtenir un meilleur score à l'échelle de Glasgow. Conclusions: Au bout de 6 mois, la mise en œuvre d'un programme de SIN a été associée, chez des patients victimes de sévères traumatismes crâniens, une amélioration de leur score à l'échelle de Glasgow.

Keywords: Traumatic brain injury, Neurocritical care, Intracranial pressure, Cerebral autoregulation, Brain tissue oxygen

doi:10.1017/cjn.2017.25

Can J Neurol Sci. 2017; 44: 350-357

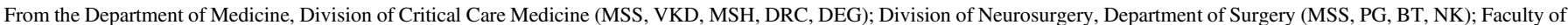
Medicine (VH); Division of Trauma Surgery, Department of Surgery (MSH); Department of Anaesthesiology, Pharmacology and Therapeutics (DEG), Vancouver General Hospital,

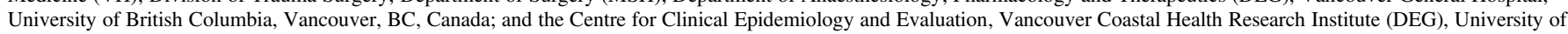
British Columbia, Vancouver, BC, Canada.

Received August 2, 2016. Final Revisions Submitted October 5, 2016. Date of Acceptance November 8, 2016.

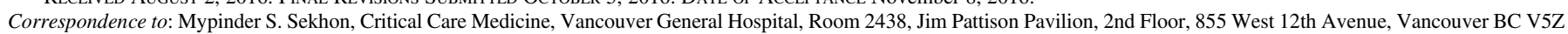
1M9 Email: mypindersekhon@gmail.com 
Neurocritical care (NCC) is a rapidly growing subspecialty of critical care medicine that focusses on the evaluation, diagnosis, and management of patients with acute life-threatening central nervous system diseases. ${ }^{1,2}$ The growth of this field has led to the development of dedicated NCC units that provide specialized multidisciplinary care for patients. Using this model, patient outcomes have improved in recent years across institutions in both Europe and North America. ${ }^{3}$

Traumatic brain injury (TBI) is a devastating disease that falls within the purview of NCC. Following severe TBI, long-term disability is common, ${ }^{4,5}$ with considerable financial societal costs for the long-term care of survivors. ${ }^{6}$ Investigators continue to search for specific interventions to improve neurologic outcomes in severe TBI. Unfortunately, studies have failed to establish firm links between single therapeutic interventions and positive patient outcomes. ${ }^{7-10}$ Despite these negative studies, TBI outcomes have steadily improved in recent years. ${ }^{11}$ The underlying explanation for this paradox is unclear, yet advances in process of care, such as protocolized management schemes aimed at effectively incorporating the additive effects of multiple therapeutic neuroprotective interventions and the development of dedicated specialized NCC units where the delivery of this care occurs, may offer an explanation. .,12-14 $^{-14}$

Unfortunately, the creation of dedicated NCC units poses many institutional challenges, including allocation of space and adequate numbers of available NCC specialists. Furthermore, specialized units have been associated with increased risk-adjusted mortality when admitting patients with an underlying primary diagnosis that is not in keeping with the specific area of dedicated expertise. ${ }^{15}$ Recently, it has been demonstrated that critical care of TBI patients within dedicated NCC units in the United Kingdom is associated with increased health care costs without a significant change in long-term neurological outcome versus combined general neurology intensive care units (ICUs). ${ }^{16}$

Although it appears that provision of NCC expertise improves long-term neurologic outcomes, ${ }^{3}$ the optimal model for providing that care remains unclear. In 2014, we developed a consultancy NCC program within our closed mixed medical-surgical ICU. In addition to providing consultation on patients with TBI, we implemented an invasive multimodal neuromonitoring program consisting of brain tissue oxygen $\left(\mathrm{PbO}_{2}\right)$ and autoregulation monitoring. The aim of this study was to examine the impact of implementing a dedicated NCC program, consisting of a collaborative model of care amongst the consulting neurosurgeon and neurointensivist with a primary care attending intensivist in a general mixed medical-surgical ICU, on long-term neurologic outcomes on patients admitted with severe TBI. Additionally, we evaluated the effects of the NCC program on the process of care metrics, including hemodynamic, neurophysiologic and temperature management, duration of intravenous sedation, mechanical ventilation, and intensive care admission.

\section{MeTHODS}

We performed a single-center quasi-experimental uncontrolled before-and-after study in keeping with the Strengthening the Reporting of Observational Studies in Epidemiology statement. ${ }^{17}$ This study was approved by both University of British Columbia and hospital clinical research ethics boards who waived the requirement for written informed consent (H16-01100).

\section{Study Population and Hospitals}

We defined our cohort as patients admitted to the ICU at Vancouver General Hospital (31 beds) between February 2010 and May 2016 with a diagnosis of severe TBI (postresuscitation Glasgow Coma Score [GCS] of 8 or lower and if an intracranial pressure [ICP] monitor was inserted). We excluded patients with bilaterally fixed and dilated pupils on admission. The ICU at Vancouver General Hospital is a closed, 31-bed mixed medical-surgical unit that operates on an approximate 1:1.2 nurse-to-patient ratio. It is staffed by fellowship-trained subspecialty critical care medicine physicians with consultant neurosurgeons in attendance and is affiliated with the University of British Columbia.

\section{Data Collection}

Patients were identified using the ICU administrative database. Data were then abstracted from the medical record into a standardized case report form in Microsoft Excel 2013 (Redmond, WA). Demographic data consisted of age, gender, and injury details (mechanism and date). Baseline data collected included: documented GCS, pupillary abnormalities, prehospital hypoxia $\left(\mathrm{SpO}_{2}<92 \%\right)$ or hypotension (systolic blood pressure $<90 \mathrm{mmHg}$ ), and Rotterdam computed tomography head score. ${ }^{18}$ The following daily ICU management data were collected and averaged for the first 7 days: mean arterial pressure (MAP), daily mean ICP, temperature $\left({ }^{\circ} \mathrm{C}\right)$, and use of medications (propofol, norepinephrine, neuromuscular blockers, barbiturates, hydrocortisone, fludrocortisone, and midazolam). Additional daily averaged data collected were: intravenous fluids per day (crystalloids, colloids, red blood cells, and mannitol), laboratory values (hemoglobin, troponin, and serum sodium), ventilation parameters (peak and plateau pressure, minute ventilation, positive end-expiratory pressure), arterial blood gases $(\mathrm{pH}$, partial pressure of oxygen and carbon dioxide), and chest x-ray radiography documenting the presence of bilateral infiltrates in keeping with acute respiratory distress syndrome. Neurophysiologic data (MAP, $\mathrm{ICP}$, cerebral perfusion pressure, $\mathrm{PbO}_{2}$, and pressure reactivity index, $\mathrm{PRx}$ ) were recorded in real-time and continuously at 10 -second intervals from our bedside monitors directly onto the $\mathrm{ICM}+$ brain monitoring software program (Division of Neurosurgery, Cambridge University) for the duration of invasive monitoring. The values of each parameter were then averaged and recorded on a daily basis. Procedural data pertaining to surgical interventions (decompressive craniectomy, craniotomy, external ventricular drain, tracheostomy), medical interventions (therapeutic hypothermia, barbiturate use, days of intravenous sedation), and invasive neuromonitoring (days of monitoring, jugular venous oximetry, intraparenchymal ICP, $\mathrm{PbO}_{2}$, and PRx) were recorded in all patients. We obtained the following outcome data from the ICU database: intensive care and hospital days, duration (in days) of mechanical ventilation, and both intensive care and hospital mortality. Neurologic outcomes were recorded with the Glasgow Outcome Scale (GOS) and were determined at 6 months by telephone interview. GOS is an ordinal scale between 1 and 5 in which $1=$ death, $2=$ permanently vegetative state, $3=$ severe disability (requires help with activities of daily living), $4=$ moderate disability, and $5=$ good recovery.

\section{Implementation of the NCC Program}

Before implementing the NCC program, we used external ventricular drains (EVDs) as the sole method of ICP monitoring and 
patients were managed using TBI management protocols based on the Brain Trauma Foundation Guidelines. ${ }^{19}$ Our TBI management protocol is modeled after other published protocols ${ }^{13}$ and is presented in the supplementary appendix. The NCC program was implemented in November 2014 is based on an consultancy neurointensivist and neurosurgical model, whereas the attending intensivist maintains the primary care role for each TBI patient and within the identical geographic location of our general mixed medical and surgical ICU. At this time, we also introduced multimodal monitoring, which consists of the Camino parenchymal intracranial pressure and Licox $\mathrm{PbO}_{2}$ monitors (Integra Life Sciences, Plainsboro, NJ). EVDs were reserved as a second-tier therapy for CSF diversion with refractory intracranial hypertension. In addition, we implemented PRx monitoring using the brain monitoring software. The program prospectively records physiologic parameters from the bedside monitors (ICP, $\mathrm{PbO}_{2}$, and MAP) in real time at 10-second intervals, thereby providing a greater granularity to our data than a one per hour recording from bedside nursing flow sheets. ICM+ calculates PRx in real-time, which is a moving Pearson correlation coefficient between 30 consecutive, 10-second averaged values of MAP and corresponding ICP signals. ${ }^{20}$ Using PRx allows identification of the optimal cerebral perfusion pressure (CPP) for each patient. $^{21}$ Physiologic goals and suggested management strategies for ICP, CPP, and $\mathrm{PbO}_{2}$ are delineated in the TBI management protocol.

\section{Statistical Analysis}

We used Stata 10.0 (StataCorp, TX) for all analyses. All hypothesis tests were two-sided and a $\mathrm{p}$ value of $<0.05$ was considered statistically significant. Normally distributed data, nonnormally distributed data, and categorical data were described with mean (standard deviation [SD]), median (interquartile range [IQR]), and proportion (percent), respectively. Univariable comparisons of continuous variables were done using $t$ tests for normally distributed data and Mann-Whitney $U$ test for non-normally distributed data where appropriate. The sample size was one of convenience and designed to ensure stability around our point estimates of a multivariable model. Assuming a favorable neurologic outcome of $40 \%$, and approximately seven to eight events per covariate ${ }^{22}$ with a final model of approximately five to six covariates, a sample size of approximately 110 patients would be required. Because we had approximately 40 patients in the post-NCC group, we selected approximately 70 pre-NCC patients. To account for the competing risk of death, we calculate days free from 28 days for the following outcomes: ICU length of stay, duration of mechanical ventilation, duration of intravenous sedation, and duration of monitoring. We performed a complete-case analysis and presented the degree of missing data being when applicable.

\section{Relationship Between NCC and Continuous Variables}

To explore the relationship between NCC and daily continuous variables (MAP, CPP, ICP, temperature, hemoglobin, serum sodium, and norepinephrine dose), a linear mixed model (with patients included as a random effect) was performed. We included NCC as an indicator variable.

\section{Relationship Between NCC and Neurologic Outcomes}

We used multivariable ordinal logistic regression to model the association between NCC program implementation (as a dichotomous variable) and GOS as an ordinal variable. We chose the following covariates a priori for their potential to confound the relationship between NCC and GOS: age in years, admission GCS motor score, pupillary abnormalities (present or absent), Rotterdam score per 1-unit increase, and male gender. Fractional polynomial regression was used to determine the best functional form to include continuous covariates in the final multivariable model. All continuous variables were included in linear covariates. The proportionality assumption was tested using a likelihood-ratio test of proportionality of odds across the response categories.

Finally, we sought to determine which downstream variables may be responsible any association between NCC and GOS. As such, we performed a mediation analysis to determine the percentage of the total effect attributable to the chosen mediators. ${ }^{23}$ For the purpose of this analysis, we chose readily measurable mediators that were significantly different from one another before and after implementation of NCC: temperature, MAP, and serum sodium concentration. We modeled the direct variable (NCC) and indirect variables (temperature, MAP, and serum sodium) on a dichotomized favorable neurologic outcome (GOS 4 or 5) as described by Buis. ${ }^{23}$

\section{RESULTS}

Database search revealed 76 patients before implementation of the NCC program (February 2010 to October 2014) and 39 patients following implementation of the NCC program (November 2014 to May 2016). Two patients with fixed and dilated pupils were excluded (both in the post-NCC group), leaving a total of 113 patients included in the final analysis. The overall age of the cohort was 39 years (SD, 17) and 87 of 113 $(77 \%)$ were male. The median admission GCS motor score was 3 (IQR, 1-4). All injuries were blunt, with falls and motor vehicle accidents being the most frequent mechanism of injury. The baseline characteristics of the cohort are presented in Table 1. Serum ethanol levels were present in 25 of 76 (33\%) and 9 of 37 (24\%) pre- and post-NCC, respectively. In patients in whom ethanol was detected, the median level was $43 \mathrm{mmol} / \mathrm{l}$ (29-64) pre$\mathrm{NCC}$ and $10 \mathrm{mmol} / \mathrm{l}$ (IQR, 4-50) post-NCC.

\section{NCC Program and Physiologic Measures}

Physiologic measures pre and post-NCC are displayed in Figure 1. Daily MAP was higher post-NCC (95 mmHg [SD, 10]) than pre-NCC $(88 \mathrm{mmHg}$ [SD, 10], $\mathrm{p}<0.001)$. Post-NCC was also associated with increased norepinephrine dose $(p=0.002)$, but there was no difference in daily troponin levels between the two groups $(\mathrm{p}=0.54)$. Post-NCC was associated with lower mean temperature $\left(36.6^{\circ} \mathrm{C}[\mathrm{SD}, 0.90]\right)$ compared with pre-NCC $\left(37.2^{\circ} \mathrm{C}\right.$ [SD, 1.0], $\mathrm{p}=0.001)$. There was no difference between ICP or hemoglobin concentration comparing Pre-NCC and Post-NCC.

\section{Duration of Monitoring, Sedation, ICU, and Mechanical Ventilation}

The clinical interventions and outcomes for the study population are presented in Table 2. EVDs were used in all patients pre-NCC and in 14 of $37(41 \%)$ post-NCC $(\mathrm{p}<0.0001)$. Patients post-NCC had fewer days of mechanical ventilation (9 [SD, 6-9] vs 12 [SD, 7-17], $\mathrm{p}=0.029$ ), days of intravenous sedation (5 [SD, 3-6] vs 7 [SD, 4-11], $\mathrm{p}=0.0008)$, and days of ICP monitoring 
Table 1: Baseline characteristics of cohort

\begin{tabular}{l|c|c|c}
\hline & $\begin{array}{c}\text { Total } \\
\text { cohort } \\
(\mathbf{n = 1 1 3})\end{array}$ & $\begin{array}{c}\text { Pre-NCC } \\
(\mathbf{n}=\mathbf{7 6})\end{array}$ & $\begin{array}{c}\text { Post-NCC } \\
(\mathbf{n}=\mathbf{3 7})\end{array}$ \\
\hline Age in years, mean (SD) & $39(17)$ & $40(17)$ & $36(17)$ \\
\hline Male gender, $\mathrm{n}(\%)$ & $87(77)$ & $28(76)$ & $59(78)$ \\
\hline Admission hypotension, $\mathrm{n}(\%)$ & $40(35)$ & $20(26)$ & $20(54)$ \\
\hline Admission hypoxemia, $\mathrm{n}(\%)$ & $26(23)$ & $11(14)$ & $15(41)$ \\
\hline GCS median motor score (IQR) & $3(1-4)$ & $3(1-4)$ & $4(1-4)$ \\
\hline Motor score 1, n (\%) & $37(33)$ & $24(32)$ & $13(35)$ \\
\hline Motor score 2, n (\%) & $8(7)$ & $4(5)$ & $4(11)$ \\
\hline Motor score 3, n (\%) & $13(12)$ & $12(16)$ & $1(3)$ \\
\hline Motor score 4, n (\%) & $34(30)$ & $23(30)$ & $11(30)$ \\
\hline Motor score 5, $\mathrm{n}(\%)$ & $13(12)$ & $8(11)$ & $5(14)$ \\
\hline Motor score 6, $\mathrm{n}(\%)$ & $8(7)$ & $5(7)$ & $3(8)$ \\
\hline One pupil nonreactive, $\mathrm{n}(\%)$ & $33(29)$ & $23(30)$ & $10(27)$ \\
\hline Any ethanol detected on admission, $\mathrm{n}(\%)$ & $34(30)$ & $25(33)$ & $9(24)$ \\
\hline Mechanism of injury, $\mathrm{n}(\%)$ & & & \\
\hline Motor vehicle or motorcycle accident & $34(30)$ & $31(41)$ & $14(38)$ \\
\hline Accidental fall & $45(40)$ & $23(30)$ & $11(30)$ \\
\hline Pedestrian or cyclist struck & $24(21)$ & $15(20)$ & $9(24)$ \\
\hline Other & $10(9)$ & $7(9)$ & $3(8)$ \\
\hline Rotterdam score, median (IQR) & $3(3-4)$ & $3(3-4)$ & $4(3-4)$ \\
\hline & & &
\end{tabular}

(5 [SD, 3-6] vs 7 [SD, 4-7], $\mathrm{p}=0.0001$ ). There was no difference before and after NCC in the duration of intensive care admission or hospital stay.

\section{Neurologic Outcomes}

GOS stratified by NCC is presented in Figure 2. The results of the univariable and multivariable ordinal logistic regression model are presented in Table 3. Implementation of the NCC program was associated with a 2.5 increased odds (OR, 2.5; $95 \%$ CI, 1.1-5.3; $\mathrm{p}=0.022$ ) of an improved GOS given that all other variables in the model are held constant.

\section{Mediator Analysis}

As a percentage of the total effect of NCC implementation, the attributable indirect effects of the following mediators were: temperature, 5\% (95\% CI, 3-9); MAP, 24\% (95\% CI, 16-48); and serum sodium, $15 \%$ (95\% CI, 11-28). Thus, the sum of the indirect effects of these three mediators was $46 \%$, leaving $54 \%$ of the total effect of NCC being from other factors.

\section{DISCUSSION}

In our single-center quasi-experimental uncontrolled beforeand-after study, we demonstrated improved long-term favorable neurological outcomes in patients with severe TBI following implementation of a NCC program. Furthermore, we found a significant improvement in secondary clinical outcomes following implementation of the NCC program, including decreased duration of ventilation, intravenous sedation, and days of invasive neuromonitoring. The implementation of the NCC program resulted in increased norepinephrine doses, fludrocortisone use, and MAP and decreased temperatures during the first 7 days of admission. On mediation analysis, more than half of the total benefit of NCC on favorable neurological outcomes was driven by factors other than MAP, temperature, and serum sodium.
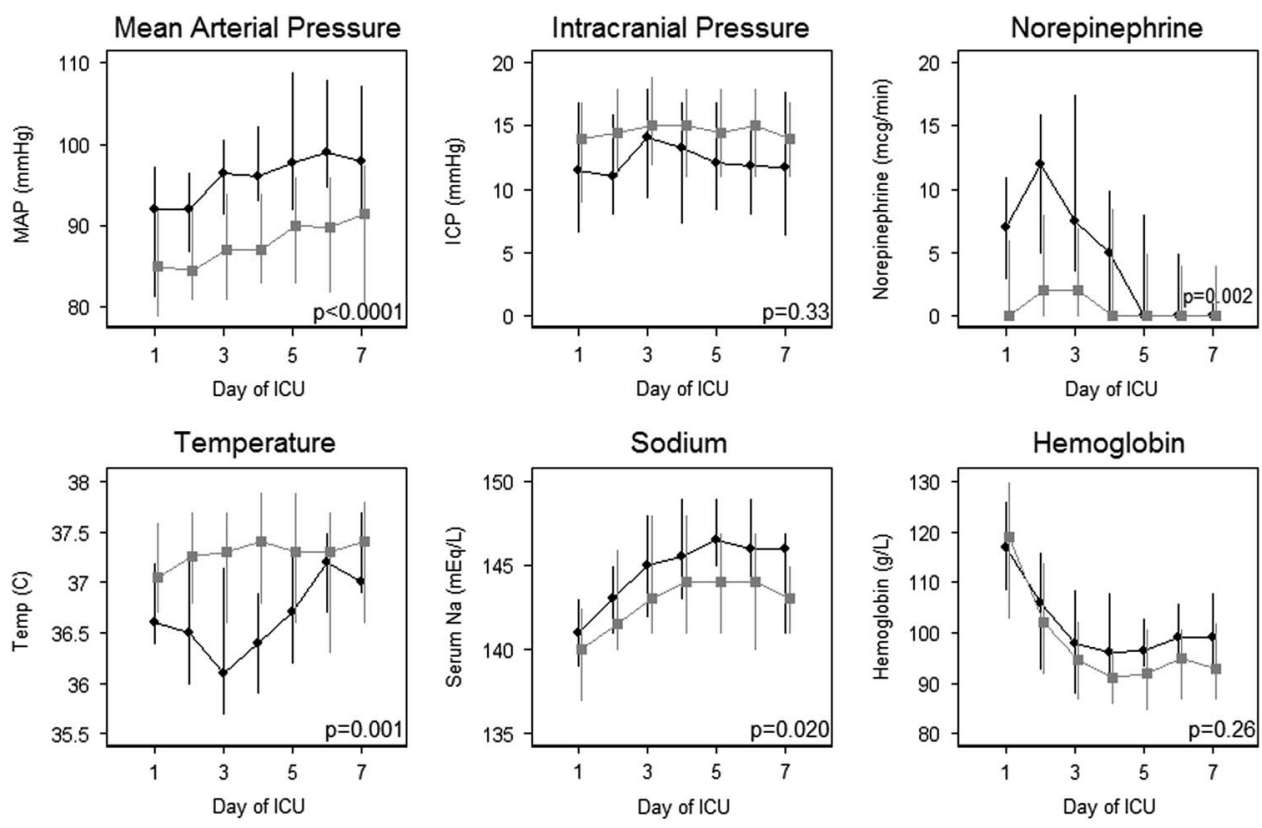

\section{$\longrightarrow$ Post NCC $\longrightarrow$ Pre NCC}

Figure 1: Differences in physiologic parameters pre-NCC versus post-NCC pertaining to daily averaged $M A P$, core body temperature, norepinephrine doses, ICP, serum sodium concentration, and hemoglobin concentration during the first 7 days of intensive care admission. 
Table 2: Clinical interventions and outcomes stratified by HTS

\begin{tabular}{|c|c|c|c|c|}
\hline & $\begin{array}{l}\text { Total cohort } \\
\quad(n=113)\end{array}$ & $\begin{array}{c}\text { Pre-NCC } \\
(n=76)\end{array}$ & $\begin{array}{l}\text { Post-NCC } \\
(\mathbf{n}=37)\end{array}$ & p value \\
\hline Parenchymal ICP catheter use, $\mathrm{n}(\%)$ & $26(23)$ & 0 & $26(70)$ & $<0.0001$ \\
\hline $\mathrm{PbO}_{2}$ catheter use, $\mathrm{n}(\%)$ & $26(23)$ & 0 & $26(70)$ & $<0.0001$ \\
\hline Jugular bulb use, $\mathrm{n}(\%)$ & $17(15)$ & $9(12)$ & $8(22)$ & 0.26 \\
\hline EVD use, $\mathrm{n}(\%)$ & $91(81)$ & $76(100)$ & $15(41)$ & $<0.0001$ \\
\hline Craniotomy performed, n (\%) & $57(50)$ & $46(61)$ & $11(30)$ & 0.003 \\
\hline Craniectomy performed, n (\%) & $38(34)$ & $28(37)$ & $10(27)$ & 0.40 \\
\hline ICU days, median (IQR) & $13(7-18)$ & $13(7-18.5)$ & $11.5(6.5-15)$ & 0.30 \\
\hline ICU-free days, median (IQR) & $13(1.5-17.5)$ & $11(0-17.5)$ & $14.5(10-18)$ & 0.17 \\
\hline Mechanical ventilation days, median (IQR) & $11(6-15)$ & $12(7-17)$ & $9(6-9)$ & 0.029 \\
\hline Ventilator-free days, median (IQR) & $14(5-20)$ & $12.5(0-18)$ & $17(13-21)$ & 0.015 \\
\hline Neuromonitoring days, median (IQR) & $6(4-8)$ & $7(4-7)$ & $5(3-6)$ & 0.0001 \\
\hline Monitoring free days, median (IQR) & $20.5(13-23)$ & $19(0-21)$ & $23(21-24)$ & 0.0001 \\
\hline Sedation days, median (IQR) & $6(4-9)$ & $7(4-11)$ & $5(3-6)$ & 0.0008 \\
\hline Sedation free days, median (IQR) & $21(0-23)$ & $18.5(3.5-22)$ & $23(20-25)$ & 0.0009 \\
\hline Median days of hospitalization (IQR) & $42(22-68)$ & $44.5(22-69.5)$ & $32.5(20-58)$ & 0.39 \\
\hline Tracheostomy performed, $\mathrm{n}(\%)$ & $69(61)$ & $50(66)$ & $19(51)$ & 0.16 \\
\hline
\end{tabular}

$\mathrm{EVD}=$ external ventricular drain; HTS = hypertonic saline.

Several controlled historical cohort studies have demonstrated improved neurologic outcomes with implementation of a dedicated NCC clinical service, albeit with several different care models in varying populations. ${ }^{3}$ Specifically, studies have shown improvements in neurologic outcomes with the creation of a distinct NCC unit with $\mathrm{TBI}^{13,14}$ and intracerebral hemorrhage $(\mathrm{ICH}){ }^{24}$ Other studies have implemented standardized management protocols aimed at incorporating multiple therapeutic interventions in a structured format. ${ }^{25}$ Yet other models have added a neurointensivists to existing dedicated NCC units in patients with subarachnoid hemorrhage, ${ }^{26,27} \mathrm{TBI}^{28}$ and stroke. ${ }^{29}$ These have also resulted in decreased mortality and improved neurological outcome. More in keeping with our report, Pineda and colleagues examined the

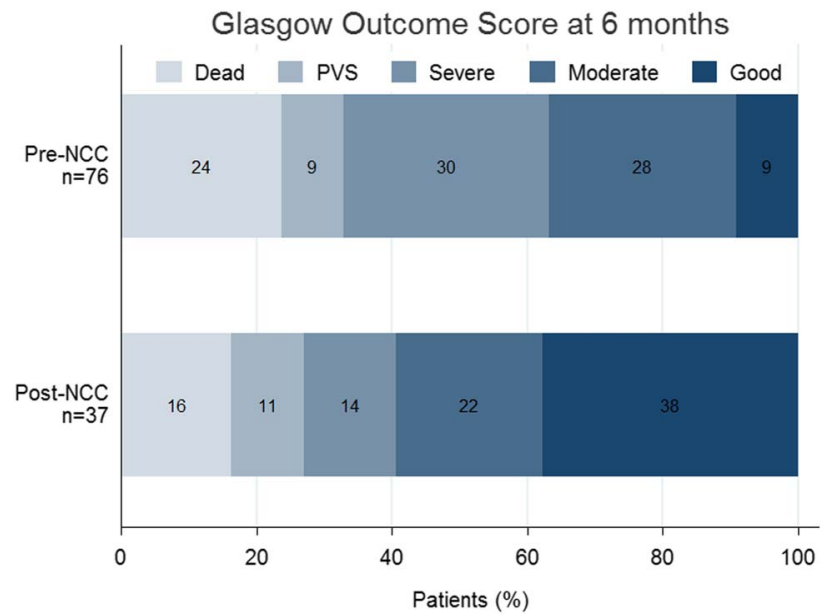

Figure 2: Differences in GOS distribution in patients with severe TBI pre-NCC versus post-NCC. Percentages for each GOS point are displayed for pre- and post-NCC. addition of a pediatric NCC program of care to an general ICU. ${ }^{30}$ This program consisted of a time-sensitive and severity-based protocolized approach to care. They demonstrated increased favorable disposition (discharged home).

In contrast to these studies, which provide care in dedicated NCC units, we developed a consultancy-based NCC program operating within an existing closed medical-surgical academic ICU. Our model for severe TBI maintains that the primary care is delivered by the attending intensivist with both neurointensivist and neurosurgeon consultation. This collaborative model was chosen for several reasons. First, there are several logistical issues with establishing a separate NCC unit, including the availability of physical space and of neurointensivist coverage and nursing and paramedical personnel. Second, the creation of a dedicated NCC unit carries significant institutional logistical challenges of physician staffing, allied health care provider training, and institutional patient bed flow challenges with boarding and out-of-ICU patient overflow. Finally, it must be recognized that caring for patients in a separate subspecialty unit could confer unexpected risk as demonstrated in a large historical cohort study of 84,182 patients in 124 specialty and general ICUs by Lott and colleagues. ${ }^{15}$ They demonstrated that for patients admitted with specific diagnoses (e.g. acute coronary syndrome, ischemic stroke, ICH, pneumonia, abdominal surgery, coronary artery bypass graft surgery), admission to a specialty ICU, compared with a nonspecialty ICU, did not offer a survival benefit. Furthermore, when examining patients with ICH $(n=3835)$ or ischemic stroke $(\mathrm{n}=2390)$, the risk-adjusted ORs for specialty ICU compared with a general ICU were 1.00 (95\% CI, 0.79-1.28) and 1.35 (95\% CI, 0.96-1.89), respectively. Lott and colleagues also demonstrated that when patients were admitted with $\mathrm{ICH}$ to a nonideal specialty ICU (e.g. ICH patient admitted to a non-NCC unit), the OR was 1.31 (95\% CI, 1.03-1.66), indicating an 
Table 3: Univariable and multivariable ordinal logistic regression for the implementation of an NCC program on 6-month GOS

\begin{tabular}{l|c|c|c|c|c|c}
\hline & \multicolumn{3}{|c|}{ Unadjusted } & \multicolumn{2}{c}{ Adjusted } \\
\hline Predictor variable & OR & $\mathbf{9 5 \%}$ CI & p value & OR & 95\% CI & p value \\
\hline NCC & 2.7 & $1.3-5.7$ & 0.009 & 2.5 & $1.1-5.3$ & 0.022 \\
\hline Age per 10-year increase & 0.66 & $0.53-0.81$ & $<0.0001$ & 0.65 & $0.52-0.81$ & $<0.0001$ \\
\hline Admission GCS motor score & 1.2 & $1.0-1.5$ & 0.045 & 1.2 & $0.92-1.5$ & 0.18 \\
\hline Pupillary abnormality & 0.33 & $0.15-0.69$ & 0.003 & 0.47 & $0.18-1.3$ & 0.13 \\
\hline Rotterdam score per 1-unit increase & 0.83 & $0.61-1.1$ & 0.23 & 1.1 & $0.78-1.7$ & 0.52 \\
\hline Male gender & 0.74 & $0.34-1.6$ & 0.46 & 0.64 & $0.28-1.4$ & 0.28 \\
\hline
\end{tabular}

increased risk of mortality. These data suggest that patients admitted to specialty ICUs may have increased risk of mortality when the admission diagnosis falls outside of the usual spectrum of care for that particular unit, a significant issue that would have been posed in our institution with the creation of a dedicated NCC unit. Therefore, we elected to create a NCC program that brought this crucial coordinated expert care to our patients within an existing geographical ICU structure.

A critical limitation when considering the results of our study is that we implemented an entire program of care, including both NCC consultation and multimodal neuromonitoring. We attempted to examine the attributable indirect effects of some of these factors using mediation analysis. We chose variables that were present both before and after implementation of the NCC program. Overall, changes in temperature, MAP, and serum sodium management accounted for less than $50 \%$ of the total beneficial effects of NCC. However, we were unable to quantify the attributable benefit to other factors such as $\mathrm{PbO}_{2}$ monitoring because these were not present before the NCC program was implemented. Furthermore, it may be that a combination of factors may be responsible for the improvements seen, a factor not accounted for in our analysis. Importantly, studies in neurocritical care have consistently failed to demonstrate that any single intervention results in improved outcomes. Examples of interventions rigorously studied with randomized trials in patients with TBI that have not demonstrated benefit include ICP monitoring, ${ }^{8}$ therapeutic hypothermia, ${ }^{10}$ decompressive craniectomy, ${ }^{7}$ liberal transfusion threshold, ${ }^{9}$ and multiple pharmacologic neuroprotective strategies. ${ }^{31,32}$ Thus, it seems unlikely that any single intervention could account for the benefit observed in our study. This belief is supported by the recent consensus summary statement of the International Multidisciplinary Consensus Conference on Multimodal Monitoring in Neurocritical Care. ${ }^{33}$ It recommends both ICP and $\mathrm{PbO}_{2}$ within the context of a structured protocol, but that patient care must be individualized. The consensus statement further states that "It is difficult to demonstrate that any single monitor or combination of monitors has a positive effect on outcome, since outcome is influenced by the therapeutic plan driven by monitoring, not by monitoring itself.",33

Thus, in keeping with these recommendations, we implemented multimodal monitoring as part of our NCC program. In addition to the ICP/CPP monitoring that was previously used in our ICU, we added both $\mathrm{PbO}_{2}$ and cerebral autoregulation monitoring using PRx. Historical cohort studies have repeatedly established associations between adverse outcome and concurrent brain hypoxia, anemia, and intracranial hypertension after TBI ${ }^{34-36}$ Furthermore, a historical cohort study by Spiotta and colleagues studies have also demonstrated improved neurologic outcomes with the addition of $\mathrm{PbO}_{2}$ to an established ICP/CPP protocol. ${ }^{37}$ We are still waiting for the publication of a completed phase 2 randomized trial comparing the addition of $\mathrm{PbO}_{2}$ targeted management strategy to an existing ICP/CPP protocol. ${ }^{38} \mathrm{We}$ also added autoregulation monitoring as part of our NCC program. Aries and colleagues established that patients who had a favorable neurologic outcome spent a great proportion of their monitoring time with their CPP maintained within $5 \mathrm{mmHg}$ of their optimal CPP as assessed by PRx. ${ }^{39}$

There are several additional limitations that need to be considered when interpreting our results. As with all quasi-experimental uncontrolled before-and-after studies, there may be a strong observer effect whereby the clinical care may improve simply by being studied. ${ }^{40}$ This study design is also subject to an overestimation of the effectiveness of the intervention. Despite our multivariable regression model to adjust for known confounders of outcome in patients with TBI, unmeasured or residual confounding may be an alternate explanation for our results. In addition, because the selection of patients for monitoring is at the discretion of the treating physician, the results may be subject to confounding by indication. This occurs when variables that are associated with outcomes in the study base are also associated with exposure variables. ${ }^{41}$ Furthermore, we attempted to contact patients at a consistent time after injury to obtain their true 6-month functional outcome. However, these outcomes were determined short of 6 months in several of the post-NCC cohort because the study was completed before the 6-month outcome. We would expect this to lead to downward bias in the post-NCC group point estimate because neurologic outcomes continue to improve with time. Finally, we did not examine the factors associated with death in the cohort. For example, there is significant variation in mortality between centers that is driven by the decision to withdraw life-sustaining therapy. ${ }^{42}$ We did not capture data on this crucial determinant of outcome; thus, the external validity of these results are limited to centers with similar practice patterns as our own.

\section{Conclusion}

Implementation of a consultancy NCC program is associated with improved clinical outcomes in patients with severe TBI who underwent invasive neuromonitoring.

\section{ACKNOWLEDGEMENTS}

We would like acknowledge the physicians, nurses, and allied health staff at Vancouver General Hospital for their contributions to the NCC program. 


\section{DisCLOSURES}

The authors do not have anything to disclose.

\section{Statement of AUthorship}

DRC contributed to manuscript preparation and data analysis. DEG contributed to manuscript preparation, data collection, and data analysis. MSS undertook study design, data collection, data analysis, and manuscript preparation. PG undertook study design, data analysis, and manuscript preparation. BT undertook data analysis and manuscript preparation. NK undertook data collection and manuscript preparation. $\mathrm{VH}$ undertook data collection and data analysis. VKD undertook data analysis and manuscript preparation. MSH undertook data analysis and manuscript preparation.

\section{SUPPLEMENTARY MATERIAL}

To view supplementary material for this article, please visit https://doi.org/10.1017/cjn.2017.25

\section{REFERENCES}

1. Korbakis G, Bleck T. The evolution of neurocritical care. Crit Care Clin. 2014;30:657-71.

2. Kramer AH, Zygun DA. Neurocritical care: why does it make a difference? Curr Opin Crit Care. 2014;20:174-81.

3. Kramer AH, Zygun DA. Do neurocritical care units save lives? Measuring the impact of specialized ICUs. Neurocrit Care. 2011;14:329-3.

4. Selassie AW, Zaloshnja E, Langlois JA, Miller T, Jones P, Steiner C. Incidence of long-term disability following traumatic brain injury hospitalization, United States, 2003. J Head Trauma Rehabil. 2008;23:123-31.

5. Langlois JA, Rutland-Brown W, Wald MM. The epidemiology and impact of traumatic brain injury: a brief overview. J Head Trauma Rehabil. 2006;21:375-8.

6. Chen A, Bushmeneva K, Zagorski B, Colantonio A, Parsons D, Wodchis WP. Direct cost associated with acquired brain injury in Ontario. BMC Neurol. 2012;12:76.

7. Cooper DJ, Rosenfeld JV, Murray L, et al. Decompressive craniectomy in diffuse traumatic brain injury. N Engl J Med. 2011;364:1493-502.

8. Chesnut RM, Temkin N, Carney N, et al. A trial of intracranialpressure monitoring in traumatic brain injury. $\mathrm{N}$ Engl $\mathrm{J}$ Med. 2012:2471-81.

9. Robertson CS, Hannay HJ, Yamal J-M, et al. Effect of erythropoietin and transfusion threshold on neurological recovery after traumatic brain injury. JAMA. 2014;312:36.

10. Andrews PJD, Sinclair HL, Rodriguez A, et al. Hypothermia for intracranial hypertension after traumatic brain injury. $\mathrm{N}$ Engl $\mathrm{J}$ Med. 2015;373:2403-12.

11. Coronado VG, Xu L, Basavaraju SV, et al. Surveillance for traumatic brain injury-related deaths-Cunited States, 1997-2007. MMWR Surveill Summ. 2011;60:1-32.

12. Elf K, Nilsson P, Enblad P. Outcome after traumatic brain injury improved by an organized secondary insult program and standardized neurointensive care. Crit Care Med. 2002;30:2129-34.

13. Patel HC, Menon DK, Tebbs S, Hawker R, Hutchinson PJ, Kirkpatrick PJ. Specialist neurocritical care and outcome from head injury. Intens Care Med. 2002;28:547-3.

14. Wärme PE, Bergström R, Persson L. Neurosurgical intensive care improves outcome after severe head injury. Acta Neurochir (Wien). 1991;110:57-64.

15. Lott JP, Iwashyna TJ, Christie JD, Asch DA, Kramer AA, Kahn JM. Critical illness outcomes in specialty versus general intensive care units. Am J Resp Crit Care Med. 2009;179:676-83.

16. Grieve R, Sadique Z, Gomes M, et al. An evaluation of the clinical and cost-effectiveness of alternative care locations for critically ill adult patients with acute traumatic brain injury. Br J Neurosurg. 2016:1-9.
17. Vandenbroucke JP, von Elm E, Altman DG, et al. Strengthening the Reporting of Observational Studies in Epidemiology (STROBE): explanation and elaboration. Epidemiology. 2007;18:805-35.

18. Maas AIR, Hukkelhoven CWPM, Marshall LF, Steyerberg EW. Prediction of outcome in traumatic brain injury with computed tomographic characteristics: a comparison between the computed tomographic classification and combinations of computed tomographic predictors. Neurosurgery. 2005;57:1173-82.

19. Bratton SL, Chestnut RM, Ghajar J, et al. Guidelines for the management of severe traumatic brain injury. $\mathrm{J}$ Neurotrauma. 2007;24:s1-106.

20. Aries MJH, Czosnyka M, Budohoski KP, et al. Continuous determination of optimal cerebral perfusion pressure in traumatic brain injury. Crit Care Med. 2012;40:2456-63.

21. Smielewski P, Aries M, Lavinio A, et al. Use of ICM + software for tracking "optimal" CPP values in real time. Eur J Anaesthesiol. 2012;29:A34.

22. Vittinghoff E, McCulloch CE. Relaxing the rule of ten events per variable in logistic and Cox regression. Am J Epidemiol. 2007; 165:710-8

23. Buis ML. Direct and indirect effects in a logit model. Stata J. 2010;10:11-29.

24. Diringer MN, Edwards DF. Admission to a neurologic/neurosurgical intensive care unit is associated with reduced mortality rate after intracerebral hemorrhage. Crit Care Med. 2001; 29:635-40.

25. Lerch C, Yonekawa Y, Muroi C, Bjeljac M, Keller E. Specialized neurocritical care, severity grade, and outcome of patients with aneurysmal subarachnoid hemorrhage. Neurocrit Care. 2006;5:85-92.

26. Josephson SA, Douglas VC, Lawton MT, English JD, Smith WS, Ko NU. Improvement in intensive care unit outcomes in patients with subarachnoid hemorrhage after initiation of neurointensivist co-management. J Neurosurg. 2010;112:626-30.

27. Samuels O, Webb A, Culler S, Martin K, Barrow D. Impact of a dedicated neurocritical care team in treating patients with aneurysmal subarachnoid hemorrhage. Neurocrit Care. 2011; 14:334-40.

28. Varelas PN, Eastwood D, Yun HJ, et al. Impact of a neurointensivist on outcomes in patients with head trauma treated in a neurosciences intensive care unit. J Neurosurg. 2006;104:713-9.

29. Varelas PN, Schultz L, Conti M, Spanaki M, Genarrelli T, HaceinBey L. The impact of a neuro-intensivist on patients with stroke admitted to a neurosciences intensive care unit. Neurocrit Care. 2008;9:293-9.

30. Pineda JA, Leonard JR, Mazotas IG, et al. Effect of implementation of a paediatric neurocritical care programme on outcomes after severe traumatic brain injury: a retrospective cohort study. Lancet Neurol. 2013;12:45-52.

31. Temkin NR, Anderson GD, Winn HR, et al. Magnesium sulfate for neuroprotection after traumatic brain injury: a randomised controlled trial. Lancet Neurol. 2007;6:29-38.

32. Wright DW, Yeatts SD, Silbergleit R, et al. Very early administration of progesterone for acute traumatic brain injury. N Engl J Med. 2014;371:2457-66.

33. Le Roux P, Menon DK, Citerio G, et al. Consensus summary statement of the International Multidisciplinary Consensus Conference on Multimodality Monitoring in Neurocritical Care: a statement for healthcare professionals from the Neurocritical Care Society and the European Society of Intensive. Int Care Med. 2014;40:1189-209.

34. Sekhon MS, McLean N, Henderson WR, Chittock DR, Griesdale DE. Association of hemoglobin concentration and mortality in critically ill patients with severe traumatic brain injury. Crit Care. 2012;16:R128.

35. Dings J, Jäger A, Meixensberger J, Roosen K. Brain tissue pO2 and outcome after severe head injury. Neurol Res. 1998;20(Suppl 1): S71-5.

36. Vik A, Nag T, Fredriksli OA, et al. Relationship of "dose" of intracranial hypertension to outcome in severe traumatic brain injury. J Neurosurg. 2008;109:678-84.

37. Spiotta AM, Stiefel MF, Gracias VH, et al. Brain tissue oxygen-directed management and outcome in patients with severe traumatic brain injury. J Neurosurg. 2010;113:571-80. 
38. Diaz-Arrastia R. Brain Tissue Oxygen Monitoring in Traumatic Brain Injury (TBI) (BOOST 2) Available at: https://clinicaltrials. gov/ct2/show/NCT00974259.

39. Aries MJ, Czosnyka M, Budohoski KP, et al. Continuous determination of optimal cerebral perfusion pressure in traumatic brain injury. Crit Care Med. 2012;40:2456-63.

40. Grimshaw J, Campbell M, Eccles M, Steen N. Experimental and quasi-experimental designs for evaluating guideline implementation strategies. Fam Pr. 2000;17(Suppl 1):S11-6.
41. Salas M, Hofman A, Stricker BH. Confounding by indication: an example of variation in the use of epidemiologic terminology. Am J Epidemiol. 1999;149:981-3.

42. Turgeon AF, Lauzier F, Simard J-F, et al. Mortality associated with withdrawal of life-sustaining therapy for patients with severe traumatic brain injury: a Canadian multicentre cohort study. CMAJ. 2011;183:1581-8. 